\title{
METABOLIC ABNORMALITIES DETECTED IN A SURVEY OF MENTALLY BACKWARD INDIVIDUALS IN NORTHERN IRELAND
}

\author{
BY \\ NINA A. J. CARSON and D. W. NEILL \\ From the Royal Belfast Hospital for Sick Children and the Royal Victoria Hospital, Belfast
}

(RECEIVED FOR PUBLICATION JUNE 8, 1962)

In 1908, Sir Archibald Garrod in his Croonian lectures coined the name inborn errors of metabolism' to describe a group of rare metabolic disorders which appeared to be genetically determined. In 1923, he described six such conditions in a monograph-alcaptonuria, pentosuria, cystinuria, albinism, pancreatic steatorrhoea and porphyria. He predicted that a biochemical reason would be found for these disorders and that they probably resulted from a block at some point in metabolism due to the congenital deficiency of a specific enzyme. The development of chromatographic and enzymatic techniques over the past 15 years has led to the elucidation of many metabolic pathways and provided the scientific proof of his brilliant induction.

Garrod thought that in alcaptonuria, the accumulation of homogentisic acid was evidence that this substance was a normal metabolite in the breakdown of tyrosine and that its increase was due to a failure of oxidation of homogentisic acid. Now, a half century later, Garrod's hypothesis has been proved by demonstration of the absence of homogentisic acid oxidase activity in the liver of a patient with alcaptonuria (La Du, Zannoni, Laster and Seegmiller, 1958).

In the past decade many abnormalities in the excretion of amino acids have been noted in association with hereditary biochemical disorders and mental retardation. Among these may be noted maple syrup urine disease (Dancis, Levitz, Miller and Westall, 1959), in which there is a metabolic block in the degradative pathway of the branched chain amino acids isoleucine, leucine and valine; this is associated with mental retardation, muscular hypertonicity and a maple syrup odour to the urine. Hartnup disease was first described by Baron, Dent, Harris, Hart and Jepson in 1956; this is characterized by a pellagra-like, light-sensitive skin rash, cerebellar ataxia and emotional instability. A constant feature of the disease is a generalized aminoaciduria related to an intermittent upset in tryptophane metabolism (Milne, Crawford, Girao and Loughridge, 1960). Harris, Penrose and Thomas (1959) described cystathionuria in an elderly mentally-retarded patient. Glycinuria has recently been described by Childs, Nyhan, Borden, Bard and Cooke (1961) where mental retardation and microcephaly were accompanied by excess glycine in urine and blood.

Metabolic errors in carbohydrate metabolism have been known for many years; pentosuria as cited by Garrod in 1908 was first described in 1892 by Salkowski and Jastrowitz. Galactosaemia was also first noted in 1908 by Reuss-although the mechanism of its occurrence was only described in 1956 by Schwarz, Golberg, Komrower and Holzel in England and Isselbacher, Anderson, Kurahashi and Kalckar in America. Gargoylism was recognized in 1917 by Hunter, but it is only within recent years that it has been discovered to be due to deviations in the metabolism of mucopolysaccharides (Dorfman and Lorincz, 1957; Meyer, Hoffman and Linker, 1957).

All these conditions are rare and there are, as yet, few specific instances in which a chemical disturbance results in mental retardation; less than $5 \%$ of the mentally defective population are of this type. With the exception of Hartnup disease, these metabolic disturbances are responsible for the more severe degrees of mental retardation. Some are amenable to treatment especially when diagnosed and treated from an early age, e.g. phenylketonuria, galactosaemia, maple syrup urine, but in them the actual cause of the brain damage is still unknown.

With the increased interest in these metabolic errors in recent years it was considered desirable to determine their incidence in Northern Ireland. With special reference to phenylketonuria it was felt that the registration of all phenylketonuric families would allow the condition to be anticipated in any new siblings so that treatment could be started at an early age when success would be more sure. 
There are approximately 4,000 mentally retarded persons in Northern Ireland who are registered as being under the supervision of the Special Care branch of the Northern Ireland Hospitals Authority. This includes those persons, irrespective of age or sex, who have an intelligence quotient below 75 , indicating mental retardation. Of all cases reported to the Special Care Service, $25 \%$ are high grade defectives with an I.Q. varying between 50-75, approximately $60 \%$ are medium grade with an I.Q. between $30-50$, and $15 \%$ are low grade.

Of these people, $50 \%$ are cared for in the community under the supervision of medical officers and social workers of the Special Care Service, the remaining $50 \%$ being cared for in residential institutions for the mentally retarded.

This paper is an interim report of studies of biochemical disturbances which cause brain damage, mainly as a result of some inborn error of metabolism. Samples of urine were obtained from the patients and every urine was subjected to a battery of simple qualitative tests in order to exclude such obvious abnormalities as excess reducing substances, proteinuria, phenylpyruvic aciduria, excess indicanuria, sulphur-containing amino acids, ketones, porphobilinogen, mucopolysaccharides, or abnormalities of calcium excretion.

Irrespective of the findings of these qualitative tests, the urinary excretion of amino acids using paper chromatographic techniques was studied. Urine was used for these tests as it is the most easily obtainable biological fluid from mentally retarded patients as well as being a rich source of metabolites. In the event of an aminoaciduria or other abnormality being detected, fresh samples of urine were obtained in order to confirm the finding before further studies were undertaken.

\section{Material and Methods}

As it was impossible in a survey of this kind to obtain absolutely fresh specimens, thymol crystals were added to the sample bottles before the urine was collected; on receipt of the urine it was stored in a refrigerator until the tests were performed.

\section{A. Qualitative Screening Tests}

Reducing substances were detected by the use of Ames Clinitest tablets. In the event of a positive reaction the urine was examined by one-dimensional chromatography to identify the carbohydrate, if present.

Phenylpyruvic acid was detected by the use of either filter paper strips impregnated with ferric chloride and buffered (Ames Phenistix), or by the ferric chloride test.

Ketones and ketoacids were detected by using the Rothera nitroprusside test in the form of the commercially available Acetest tablets, and by the addition of 2-4 dinitrophenylhydrazine solution with formation of the characteristic dinitrophenylhydrazones.
Protein was detected by addition of sulphosalicylic acid.

Sulphur-containing amino acids were detected by the sodium cyanide-nitroprusside test as described by Brand, Harris and Biloon (1930).

Porphobilinogen was detected using the Watson modification of Ehrlich's reagent, with partition in amyl alcohol/benzyl alcohol to distinguish porphobilinogen from urobilinogen.

Gross errors in bone metabolism were excluded by use of Sulkowitch qualitative reagent for calcium.

Indican (potassium indoxyl sulphate) was detected by Obermeyer's Prussian blue technique.

Urinary indican usually arises from indole formed as a result of bacterial action on dietary tryptophane in the intestine, the indole is then absorbed and transported to the liver where it is oxidized to indoxyl and conjugated to sulphate. This indican is then excreted in the urine. Urinary indican, according to Sprince (1961), is increased in many conditions such as renal insufficiency, achlorhydria, certain anaemias, intestinal ulceration, peritonitis, systemic infections and bowel stasis. Increased levels of urinary indican have also been described in Hartnup disease (Milne et al., 1960) and in phenylketonuria (Bessman and Tada, 1960). It has been suggested by C. E. Dent (personal communication) that those urines which gave a strongly positive reaction for indican might possibly have some abnormality of indole metabolism, and indicanuria was used as a rough screening test to select those urines in which further investigation for indole derivatives might prove informative.

Excess acid mucopolysaccharides: The specific staining reaction with Alcian blue was used to detect the increase in acid mucopolysaccharides found in gargoylism. A modification of the technique described by Heremans and Vaerman (1958) was adopted: $10 \mu \mathrm{l}$. urine was applied to Whatman No. 4 filter paper, dried, dipped in a solution of $1 \%$ Alcian blue dissolved in $90 \%$ glacial acetic acid and the background colour washed out with water followed by glacial acetic acid and finally water. Acid mucopolysaccharides stain bright blue against a white background.

B. Amino Acid Chromatography. All urines were examined for abnormality of amino acid excretion. The 'rack' tank of Datta, Dent and Harris (1950) was used with certain routine modifications to make their interpretation semi-quantitative. Total nitrogen estimations were performed on each urine and the volume of urine containing $250 \mu \mathrm{g}$. nitrogen was applied to each paper. Whatman's No. 1 chromatography paper was used. Each urine was desalted by electrodialysis using ion exchange membranes (Smith's modification of Wood's method, 1960) before spotting it onto the paper. The solvent system used was butanol-pyridine-water $1: 1: 1$ as a first solvent, followed by phenol ammonia as a second solvent (Smith, 1960).

The amino acids on the developed chromatogram were visualized by dipping in a $0 \cdot 1 \%$ solution of ninhydrin in acetone; they were then dried at room temperature for about 30 minutes and heated at $80^{\circ} \mathrm{C}$. for five to seven minutes. 
In order to make the results semi-quantitative $5 \mu$ l. of $x$-amino octanoic acid was applied to each paper and the density of this spot was taken to represent 5 . The density of other spots was numbered from 1 to 10 with reference to this spot. This permitted the amount of each amino acid excreted to be recorded as a figure. In view of the subjective nature of this assessment all the sheets were reviewed by one person.

To establish the normal range of values for the urinary excretion of each amino acid as detected by the above chromatographic techniques, samples from the community were picked in the following way:

All children who attended State-aided schools $\left(98^{\circ}{ }_{\mathrm{o}}\right.$ of population) in Belfast County Borough (i.e. approximately 70,000 children) and who were listed in the records of the schools ${ }^{*}$ medical service as being born on January 1 and on July 1 from 1946 to 1955 inclusive were admitted as controls, i.e. children between the ages of 5 and 15 years.

It was thought prudent to choose the dates shown to exclude the possibility of a seasonal incidence of a congenital anomaly. The age-group was chosen as being the only practicable group in which a representative sample of the population with normal intelligence could be drawn and examined. Although other workers in this field claim that there is no change in the amino acid excretory pattern with age, after the first two years of life (Bigwood, Crokaert, Schram, Soupart and Vis, 1959), it was considered advisable to examine a further sample of urines from normal adults. To do this we examined 100 samples from age-group 18-50 years; these consisted mainly of healthy nursing, medical and technical personnel of hospitals. No significant difference was found in the two age-groups.

The principal amino acids normally excreted are glycine, serine, alanine, glutamine, glutamic acid, histidine, taurine and smaller amounts of lysine, cystine, leucine, tyrosine, threonine, aspartic acid and occasionally methyl histidine. The upper and lower limits of excretion of these amino acids were determined in the above control group, a range of normality thus being established for the chromatographic techniques used.

\section{Results}

The vast majority of urines from mentally retarded persons showed an excretion of amino acids within the normal range: there were no particular patterns or trends characteristic of 'mental retardation", a fact found by other workers in this field. With a few exceptions, all the abnormalities discovered were obvious departures from the normal and left no room for doubt. The abnormalities detected in this way can be listed.

1. Phenylketonuria.

2. Argininosuccinic aciduria.

3. Homocystinuria.

4. Miscellaneous aminoacidurias.

5. Cerebral-ocular-renal syndrome of Lowe.

6. Galactosaemia.
7. Lignac-Fanconi type syndrome with mental retardation.

8. Gargoylism.

The further investigations carried out can be considered under these headings.

Phenylketonuria. This was one of the first inborn errors of metabolism to be discovered since Garrod's work on cystinuria and alcaptonuria, and is due to a rare recessive gene in homozygous form (Penrose, 1935). The abnormality was first discovered by Fölling (1934) who, when testing urines of mentally retarded people with dilute ferric chloride, found a green colour appearing in a few urines which faded on standing. This reaction was due to the large quantities of phenylpyruvic acid in the urine of these people. Jervis, Block, Bolling and Kanze (1940) established that the excretion of this substance was not the direct result of the inborn error of metabolism but that it was an abnormal metabolite from the breakdown of the amino acid phenylalanine which, due to the deficiency or lack of its specific enzyme, phenylalanine hydroxylase, could not be converted to tyrosine. but built up to high concentrations in the body and the phenylpyruvic acid production resulted from metabolism of phenylalanine by the main alternative pathway.

The diagnosis of phenylketonuria depends on the following tests:

i. $10^{\circ} \circ$ ferric chloride or 'phenistix'.

ii. Dinitrophenylhydrazine test.

iii. Presence of phenylalanine in the amino acid chromatogram.

Test i. may become negative after a period of a few days if urine is not kept cold and free from bacterial contamination, and a negative ferric chloride on an old urine is of no value. The final diagnosis is made by chromatography.

The chromatographic solvent system used (Smith, 1960) results in phenylalanine. leucine and isoleucine being superimposed on one another. In order to make sure that the spot was phenylalanine a one-dimensional chromatogram was run on a strip of Whatman No. 4 paper 22 in. long using a water saturated amyl alcohol solvent in an atmosphere of diethylamine and allowing it to run for approximately 48 hours when isoleucine. leucine and phenylalanine can all be separated out as three discrete spots. This was performed in all cases thought to be phenylketonuria.

On screening 2,081 urines, 49 cases of phenylketonuria were discovered in 36 families, 11 families having two or more siblings suffering from the disorder. Their ages ranged from 7 days to 59 years; 27 were males and 22 were females. Of the 
2,081 urines tested, 81 were from mentally deficient children directly referred from paediatric consultants and, of these, nine were phenylketonurics. If these figures are statistically treated so as to include only those individuals under Special Care, then the incidence is seen to be $2 \%$.

The majority of these cases had irreparable brain damage and were diagnosed too late to benefit from treatment. Five patients, however, received dietary treatment.

Case 1. F.J.G. was diagnosed at age 7 days; the 'phenistix' test was still negative, the dinitrophenylhydrazine test negative, but chromatography revealed a large spot of phenylalanine. This child was placed on a diet at 2 weeks of age and is making satisfactory progress at the time of writing (age 8 months). This infant was tested at this early stage as an older sibling was known to be suffering from phenylketonuria.

Case 2. A.D. was diagnosed at 3 weeks of age by the health visitor during a routine visit, using phenistix; this was confirmed by chromatography when large amounts of phenylalanine were found in the urine and blood.

Case 3. E.G. was diagnosed at $2 \frac{1}{2}$ years, her parents having brought her to hospital owing to retarded development (she did not sit up unaided until age of 18 months) and had minor convulsions. She was placed on a diet and is now aged 7 years with an I.Q. of 87.

Case 4. E.N. Although this child had a brother who was known to be suffering from phenylketonuria she did not come to the attention of the paediatrician until she was 8 months old. She did not appear to be very retarded and she was immediately put on to the special diet. Dietary management has been difficult in this case as the child showed marked dislike for the taste of her special food and a period of tube-feeding for six months was required after which oral feeding was recommenced successfully. She is now aged $3 \frac{1}{2}$ years and although formal testing was not possible the psychologist reports 'good enough normal behaviour and ability for her age'.

Case 5. G.McM. was diagnosed at 10 days. There were two other mentally retarded siblings in the family, both suffering from phenylketonuria. The child is now aged 7 years, is progressing satisfactorily and is attending ordinary school. She still remains on her phenylalanine-restricted diet.

Argininosuccinic Aciduria. This was first described in 1958 by Allan, Cusworth, Dent and Wilson. The clinical findings are mental retardation, nonprogressive ataxia with abnormal electroencephalogram pattern which may be associated with epileptic fits, abnormal friable hair, possible systolic murmurs, and excretion in the urine of argininosuccinic acid in large quantities.
Two cases of argininosuccinic acid excretors were discovered from one sibship. They are at present being investigated; both were very slow to walk and one has had intensive investigation carried out a few years ago because of ataxia. They were mentally retarded and large amounts of argininosuccinic acid were found in their urine. Fig. 1a shows a chromatogram with a large spot of argininosuccinic acid.

Homocystinuria ( 2 cases). ${ }^{*}$ This appears to be a metabolic error, previously undescribed, occurring in two female siblings, aged 5 and 7 years. There is one other normal male sibling aged 2 years. The findings were similar in the two cases with a few exceptions.

Case Reports. Both girls had a history of fits, their developmental milestones were slow and they were both severely mentally retarded. On physical examination the similarity in their appearance was very striking. They were dull looking, obviously mentally retarded children with fair hair, very red cheeks and knock knees. Their hair was abnormal in that it grew very slowly, and especially round the occiput where it broke off after only a few inches of growth. There was a peculiar mottling of the skin similar to ephelis ab igne and this was especially noticeable on lower limbs. The skin tended to be rather dry especially on the extensor surfaces of the arms. Both children had dislocated lenses, causing marked iridodonesis on movement of the pupils. There was nothing abnormal in the respiratory or cardiovascular systems. The older child had a protuberant abdomen with hepatomegaly.

The following investigations were carried out:

A radiograph of the skeleton was normal; audiometry tests were normal; E.E.G. normal; E.C.G. normal; I.Q. 30 .

Liver biopsy in older child showed fatty degeneration.

Biochemistry tests were normal, except for two liver enzymes, isocitricdehydrogenase and leucine aminopeptidase, both of which were raised on two occasions.

Haematological investigation revealed a moderate macrocytic normochromic anaemia more pronounced in the child with hepatomegaly.

Routine screening tests revealed a positive sodium nitro-prusside-cyanide test indicating an increased excretion of a sulphur-containing amino acid. Amino acid chromatography at this stage showed a normal chromatogram but on oxidizing the urine after application to the filter paper with peroxide and ammonium molybdate the chromatogram showed what appeared to be an increase in cysteic acid with an otherwise normal picture (Fig. 1b). On repeating the chromatogram with added L-cystine and oxidizing, only one spot in the cysteic acid position was seen.

* Since this paper was written a further five cases of homocystinuria have been found in three sibships. These will be the subject of a further report. 


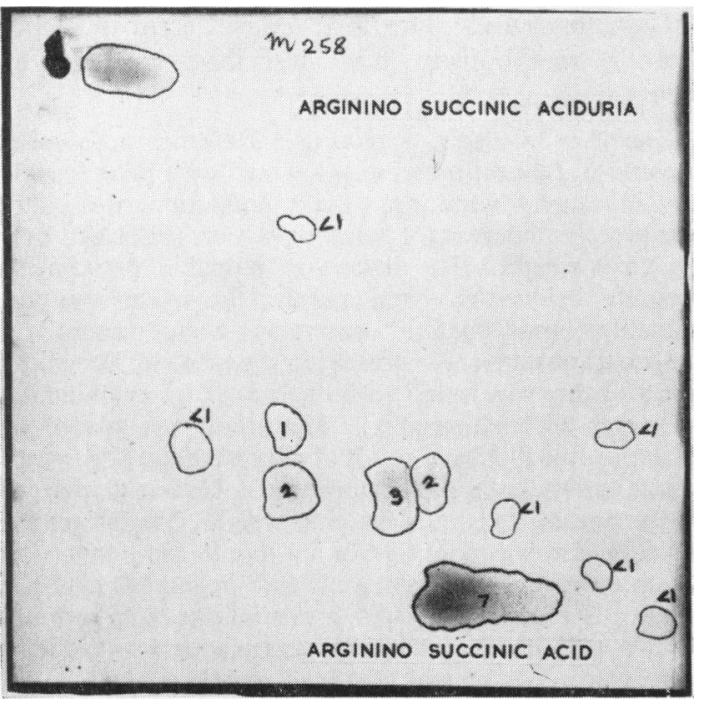

FIG. 1a.-Argininosuccinic acid.

The only conditions so far known where there is a marked increase in cystine excretion are: (1) cystinuriahere the overexcretion of cystine is accompanied by an increase in the excretion of the basic amino acids, lysine, ornithine and arginine; and (2) Wilson's disease and Lignac-Fanconi disease where the cystinuria is part of a marked general aminoaciduria.

The older child presented with hepatomegaly, and excess cystine excretion in mild liver disease has been described (Dent and Walshe, 1951). It was however felt that this finding in two siblings showing similar clinical features merited further study and accordingly specimens of the urines were sent to Professor Dent's group at the University College Hospital Medical School, London, who qualitatively confirmed the overexcretion of cystine. However, on submitting 24-hour specimens to Professor Dent for quantitative study it was discovered that the amino acid involved was not cystine but homocystine. At the same time the chromatograms were repeated here, having given one of the children a loading dose of L-cystine, and in the oxidized papers it was discovered that there were in fact two spots side by side in the cysteic acid position, one of these being homocysteic acid. Further metabolic studies are being undertaken at present in these two children in association with University College Hospital, London.

Miscellaneous Aminoacidurias. In the 2,081 urines examined there were two cases of very severe generalized aminoaciduria and 36 cases of moderate severity; these latter are of 'central cluster' pattern involving glycine, serine, alanine, glutamine and/or glutamic acid, histidine, threonine and sometimes taurine.

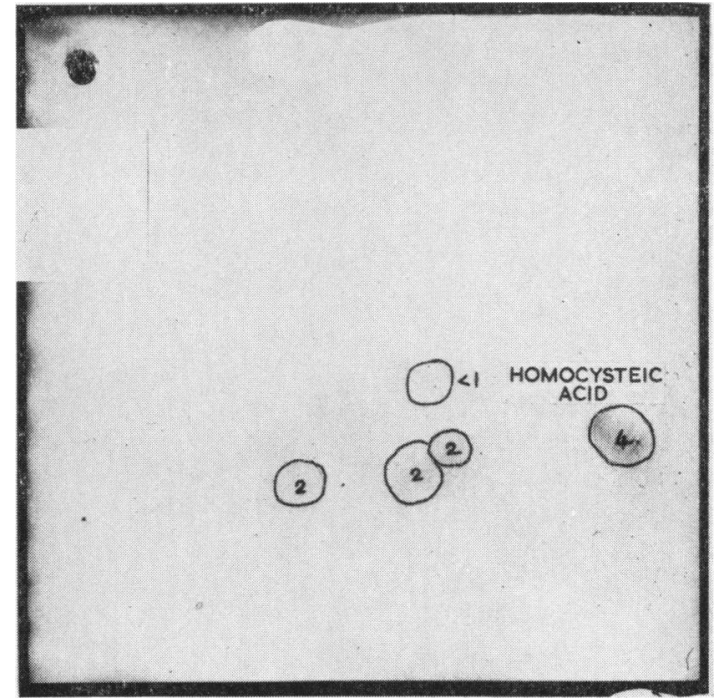

FIG. 1b.-Homocysteic acid.

There is a further miscellaneous group of specific aminoacidurias, e.g. excess glycine with other amino acids being present in normal quantities; this has recently been described in association with mental retardation by Childs et al. (1961). Alaninuria and histidinuria were also observed. This latter may be associated with dietary factors, since it is known that histidinuria may be present after a heavy protein meal especially in children; it is also increased during pregnancy (Soupart, 1954) and at the beginning of the luteal phase of the menstrual cycle (Soupart, 1960). However, Ghadimi, Partington and Hunter (1961) have described a familial disturbance of histidine metabolism in two sisters, one of whom had markedly retarded speech.

In three of the $\mathbf{4 4 4}$ normal control urines and in eight of the 2,081 urines from mentally retarded patients, a pattern suggesting cystinuria was observed on the amino acid chromatograms. This consisted of excess cystine accompanied by excess of one or more of the basic amino acids, lysine, ornithine and arginine.

It is appreciated that many of the above aminoacidurias may have a metabolic basis quite unrelated to mental retardation, and it is hoped to study these cases in detail.

Cerebral-ocular-renal Syndrome of Lowe. This syndrome was described in 1952 by Lowe, Terrey and MacLachlan from Boston. The main findings in the syndrome are mental retardation, acidosis, eye changes (hydrophthalmos, glaucoma and /or 


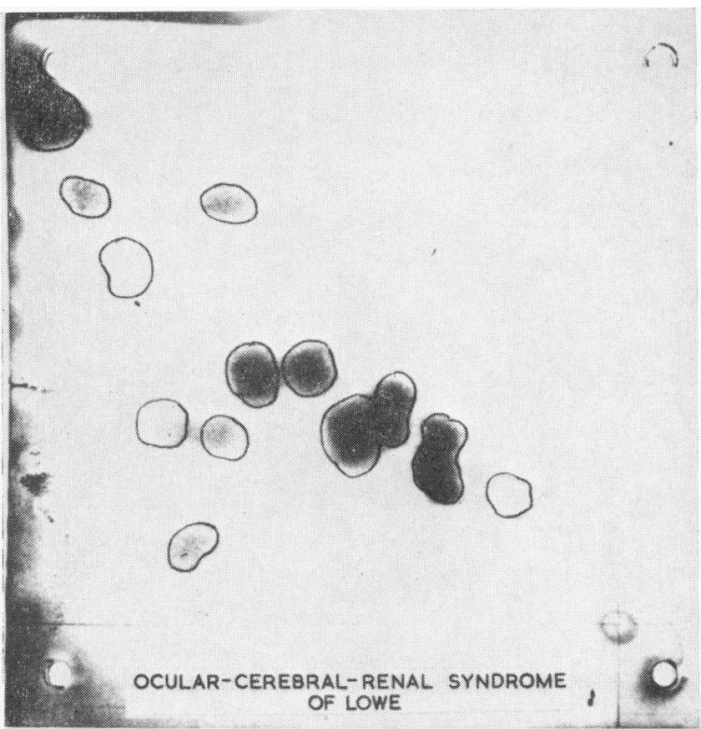

FIG. 1c.-Ocular-cerebral-renal syndrome of Lowe.

cataracts), aminoaciduria, albuminuria (no glycosuria), reduced ability of the kidneys to form ammonia, and in the untreated cases, rickets and osteomalacia.

Case Report. One case of this syndrome was discovered in a male child aged 4 years, who first came to the notice of the paediatrician with what was thought to be nephritis. The child was mentally retarded and bilateral cataracts were present which were first noticed at the age of 3 days and have been needled on three occasions. The other symptoms present were as described above. There was a severe kidney lesion with albuminuria, gross general aminoaciduria (no glycosuria), reduced ability of kidneys to form ammonia, rickets and the serum alkali reserve always in the acidotic range. This patient is the fourth and only surviving child. The first sibling died a few hours after birth from exposure as no one was with the mother at the birth; the second died at 9 days with haemorrhagic diathesis and convulsions. The third sibling had cataracts which were noticed during the first few days of life. He was not a robust baby and soon after an operation for extraction of carious teeth at the age of $3 \frac{1}{2}$ years the child died, his condition undiagnosed.

Fig. 1c shows the aminoaciduria found in this case compared with that of a normal pattern. The chromatogram shows a general aminoaciduria with special predominance of alanine, glutamine and serine; the 'nephrosis peptide' (Dent, 1948) was also present.

On the question of treatment, all one can hope to do is to keep the bony changes in check by a large intake of vitamin D and alkalis. This has caused arrest of the rickets in this child, but there has been no improvement in his mental state or cataracts.
Galactosaemia. This is an inborn error in carbohydrate metabolism, first described in 1908 by Reuss.

Case 1. S.C. aged 3 months. Referred to hospital because of failure to thrive associated with poor feeding and infrequent vomiting. On examination, the infant was grossly underweight being only $8 \mathrm{oz} .(0 \cdot 23 \mathrm{~kg}$.) over his birth weight. His liver was palpable two fingerbreadths below the costal margin, the spleen was just palpable, and bilateral cataracts were present. A reducing substance was present in the urine by Benedict's test and this was found to be galactose on examination by paper chromatography. The infant was placed on a lactose-free diet, as a result of which the liver decreased in size and the cataracts disappeared. He was discharged at the age of 9 months, gaining weight, but his mental development was only that of a 4-month-old infant. At 20 months he was reviewed and appeared to be a physically normal child with a mental age of 15 months. He was still on his diet and his urine showed no reducing substances.

Case 2. J.C., brother of S.C., aged 9 years. This child came to our attention only after his younger brother had been diagnosed as suffering from galactosaemia. He was mentally retarded with a mental age of 5 years. At birth he was a slow feeder but apart from this there was little else of note in the early history. Cataracts of both eyes were present from just under 1 year, and his developmental milestones were slow. He sat up at 10 months, talked at 4 years and had poor sphincter control. On the first occasion his urine was examined no galactose was found, but on repeating the examination at a later date he was found to be excreting galactose. On the performance of a modified galactose tolerance test he was found to handle the galactose in an abnormal manner. There were four other normal siblings in the family.

Case 3. N.C., first seen at 4 weeks with jaundice and umbilical sepsis; she was treated with antibiotics. When next seen at age 3 months she was pale and listless and had diarrhoea and frequent vomiting. On investigation she was found to be excreting a reducing substance in her urine, which proved to be galactose. The child is now normal physically and mentally and is attending ordinary school; she is still on a lactose-free diet.

This error in metabolism is inherited as an autosomal recessive, and heterozygotes of the trait may be detected by estimation of their galactose-1-p uridyl transferase activity, the level of which lies between the extremely low levels of the galactosaemic and that of a normal individual. The cases recorded here were diagnosed by finding a reducing substance in the urine, which was proved by chromatography to be galactose (Fig. 1d).

Lignac-Fanconi Type Syndrome Associated with Mental Retardation. The following case report illustrates the condition. 
Case Report. Boy, A.S., aged 7 years. Only child of unrelated parents. In the 12 months before his death this child showed many of the symptoms and biochemistry associated with Lignac-Fanconi disease (Bickel, Smallwood, Smellie and Hickmans, 1952). Renal tubular damage was evident as seen by polyuria and excessive thirst, albuminuria, intermittent mild glycosuria, aminoaciduria and hypopotassaemia. Urea was normal. Sodium cyanide/nitroprusside test was strongly positive, indicating the excretion of a large amount of sulphur-containing amino acid. A chromatogram of the urine showed a moderately severe generalized aminoaciduria of mainly central pattern, cystine being present in large quantities. Radiographs showed a generalized decalcification of the skeleton. This was associated with low to normal calcium, normal phosphorus and alkaline phosphatase, and a persistently low alkali reserve. Steatorrhoea was present. Cataracts and dislocation of lenses of both eyes were present. No cystine crystals were noted under slit-lamp examination. The child was mentally retarded.

Hepatomegaly was present associated with liver dysfunction as seen by abnormal results of bromsulphalein dye test, iso-citric-dehydrogenase and the prothrombin. Liver biopsy showed the presence of fatty degeneration; this has been described by Bickel et al. (1952), and one interesting case associated with cirrhosis of liver was reported by Baber (1956). The unusual finding in this case was cyanosis of the face and extremities, which was continuously observed; this was accompanied in the last year of his life by severe thrombotic attacks of first one limb and then another; these necessitated admission to hospital and treatment with antibiotics and anticoagulants. No cardiac lesion could be detected. There was generalized wasting and poor muscle tone and walking became progressively difficult.

The child unfortunately died at home, aged 8 years, the parents refusing any more admissions to hospital, and no autopsy was performed.

There was no family history of any mental retardation or of the above disease. Mental retardation has not been described in association with the Lignac-Fanconi disease and may well represent an incidental finding.

The amino acid chromatogram showed a generalized aminoaciduria with an especially marked cystine excretion. Serum chromatogram of amino acids in this case showed a normal pattern, the aminoaciduria therefore being of renal origin.

Gargoylism or Hurler's Syndrome. This is a metabolic error involving polysaccharide metabolism (Hurler, 1919).

Case 1. G.G. shows all the clinical manifestations of the syndrome. Diagnosed at 7 months by typical skeletal deformities and radiographs. Screening tests were positive. Severe mental retardation is now present at age 3 years.

Case 2. A.McM. Referred to the paediatric consultant at the age of 3 weeks with a congenital heart

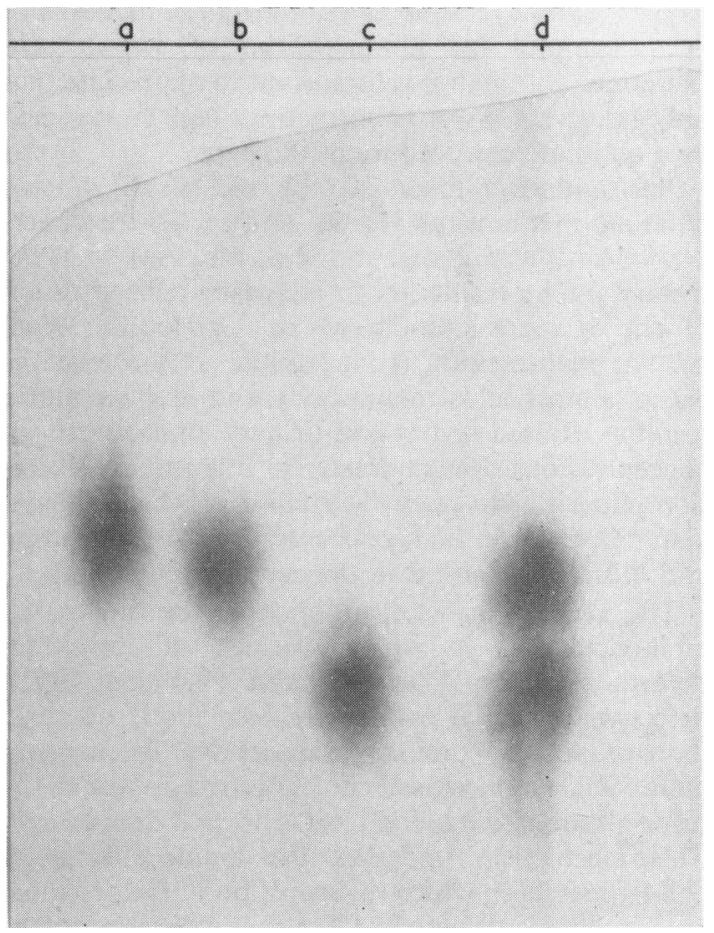

FIG. 1d.-(a) Patient's urine.

(b) Patient's urine + galactose.

(c) Normal urine + glucose.

(d) Galactose + glucose.

lesion. She was next seen at the age of 14 months when typical features of gargoylism were apparent and mental retardation was evident. Screening tests were positive.

Case 3. D.P. first came to the attention of the paediatrician at the age of 17 months because of repeated upper respiratory infections and progressive deafness which was first apparent at the age of 6 months. The appearance of the child was typical of the above condition; hepatosplenomegaly was present, radiographs showed typical joint deformities, some opacity of cornea was present and the child appeared to be backward. Screening tests were positive.

\section{Discussion}

The description by Fölling (1934) of oligophrenia phenylpyruvica and the elucidation of the enzyme defect involved amply confirmed the earlier work of Garrod on metabolic errors and gave a powerful stimulus to the search for metabolic bases of mental deficiency. In this context the metabolism of amino acids as revealed by abnormalities of urinary excretion has been a fruitful field of research and various metabolic errors have been detected.

The technique of multiple chromatography on 
paper makes it feasible to examine large numbers of urine samples for abnormalities of amino acid excretion, although it is important to appreciate that only relatively gross abnormalities can be detected by a qualitative procedure of this type.

The aminoacidurias can be the result of two different mechanisms (Dent, 1947). In the 'overflow' type, some change in the metabolism or in the dietary intake results in an increased concentration of one or more amino acids in the blood. Renal tubular reabsorption is inadequate to conserve the excess amino acids to the body and aminoaciduria results. Raised serum and urinary amino nitrogen concentrations thus characterize this urinary excretion pattern as in phenylketonuria in which phenylalanine occurs in high concentrations in both urine and blood and indeed in the cerebrospinal fluid.

The second mechanism operates in the 'renal' aminoacidurias, in which, because of congenital deformity (Clay, Darmady and Hawkins, 1953), defective proximal tubular reabsorption, or toxic damage to the tubular reabsorptive mechanism, amino acids in increased concentration appear in the urine although the blood level is normal or even low. This mechanism underlies the aminoaciduria of galactosaemia in which reabsorption in the proximal renal tubule is defective. The characteristic pattern of amino acid excretion in Lignac-Fanconi disease has been ascribed to a congenital renal deformity. The effects of toxicity can be more complex. The renal lesions resulting from the copper abnormality in Wilson's disease combine with the hepatic changes to produce an aminoaciduria which again is characteristic of the condition.

In the present study, as might be expected, metabolic disorders involving aminoacidurias of both types have been found. Overflow aminoaciduria is present in phenylketonuria and argininosuccinic aciduria. In the cerebro-oculo-renal syndrome of Lowe and in Lignac-Fanconi disease the aminoaciduria is renal in origin.

Of the clearly definable clinical entities found in the 2,081 patients examined the most common has been phenylketonuria with an incidence of $2 \%$. Jervis (1953) lists the incidence of phenylketonuria as reported from different countries and our figure of $2 \%$ is high compared to those presented, with the exception of the figure of $2.7 \%$ reported by Cowie (1951). The series on which this study was based however was small and the figure may thus be unrepresentative. As only $50 \%$ of Special Care patients have been examined, and until the study is complete, it would be fruitless to speculate on the reasons for this figure of incidence. It has, however, been possible to make use of the results so far obtained as a guide to the initiation of early treatment in newborn sibs.

The other less common conditions which have been detected on the basis of the aminoacidurias to which they give rise are being investigated further, and their discovery in this series is at once a justification for the study and a stimulus to continue it.

In employing aminoaciduria as an indicator of metabolic disorder, it is of course important to appreciate that it is not itself the disorder, that it may represent a secondary and minor feature of the abnormality of metabolism, as in galactosaemia, and that many such abnormalities do not give rise to an aminoaciduria. The suggestion by $\mathrm{H}$. Sobotka (personal communication) that formes frustes of gargoylism may occur undiagnosed led to the inclusion of a simple screening test for excess concentration of urinary mucopolysaccharide in the group of tests carried out on all the urine samples in this series. The difficulties of the clinical diagnosis suggest that much work remains to be done to devise simple screening tests sensitive enough to detect formes frustes and heterozygous forms of metabolic disorders giving rise to mental defects.

\section{Summary}

Urines from 2,081 mentally retarded individuals in Northern Ireland have been examined by qualitative chemical tests and chromatographic techniques in order to detect any inborn errors of metabolism which might be a contributory factor responsible for the brain damage in these people.

The following abnormalities were discovered: phenylketonuria, 49 cases; argininosuccinic aciduria, two cases; cerebro-ocular-renal syndrome of Lowe, one case; galactosaemia, three cases; gargoylism, three cases; Lignac-Fanconi syndrome, one case, a so far undescribed abnormality in cystine metabolism, homocystinuria, and a miscellaneous collection of general and specific aminoacidurias which are at present under investigation.

This work has been made possible by a research grant from the Royal Belfast Hospital for Sick Children.

We wish to thank Professor F. M. B. Allen, Professor of Child Health, Queen's University, Belfast, who was the instigator of this research, and the many consultants who referred cases to us, especially Dr. Joan B. T. Logan, Dr. W. A. B. Campbell and Dr. Claude Field. Special thanks are due to Dr. T. W. H. Weir, Dr. B. P. Glancy, Dr. V. O'Sullivan and Dr. W. R. Moffatt, consultants in charge of Special Care Divisions, and all the many nursing staff and social workers who have taken such trouble to collect samples of urine for this work.

We are especially indebted to Professor C. E. Dent and his group at University College Hospital for their continued interest, guidance and practical help with the many problems that have arisen in this study. 
REFERENCES

Allan, J. D., Cusworth, D. C., Dent, C. E. and Wilson, V. K. (1958). A disease, probably hereditary, characterised by severe mental deficiency and a constant gross abnormality of aminoacid metabolism. Lancet, 1, 182.

Baber, M. D. (1956). A case of congenital cirrhosis of the liver with renal tubular defects akin to those in the Fanconi syndrome. Arch. Dis. Childh., 31, 335.

Baron, D. N., Dent, C. E., Harris, H., Hart, E. W. and Jepson, J. B. (1956). Hereditary pellagra-like skin rash with temporary cerebellar ataxia, constant renal amino-aciduria, and other bizarre biochemical features. Lancet, 2, 421.

Bessman, S. P. and Tada, K. (1960). Indicanuria in phenylketonuria. Metabolism, 9, 377.

Bickel, H., Smallwood, W. C., Smellie, J. M. and Hickmans, E. M. (1952). Cystine storage disease with aminoaciduria and dwarfism (Lignac-Fanconi disease). Acta paediat., 42 (Suppl. 90), 27.

Bigwood, E. J., Crokaert, R., Schram, E., Soupart, P. and Vis, H. (1959). Amino aciduria in normal subjects. Section 3, 2: Amino aciduria in children, in infancy and prematurity. Advanc. clin. Chem., 2, 223.

Brand, E., Harris, M. M. and Biloon, S. (1930). Cystinuria; excretion of cystine complex which decomposes in urine with liberation of free cystine. J. biol. Chem., 86, 315.

Childs, B., Nyhan, W. L., Borden, M., Bard, L. and Cooke, R. E. (1961). Idiopathic hyperglycinemia and hyperglycinuria: a new disorder of amino acid metabolism. Pediatrics, 27, 522.

Clay, R. D., Darmady, E. M. and Hawkins, M. (1953). The nature of the renal lesion in the Fanconi syndrome. J. Path. Bact., 65,551 .

Cowie, V. (1951). Phenylpyruvic oligophrenia. J. ment. Sci., 97, 505.

Dancis, J., Levitz, M., Miller, S. and Westall, R. G. (1959). 'Maple syrup urine disease'. Brit. med. J., 1, 91 .

Datta, S. P., Dent, C. E. and Harris, H. (1950). Apparatus for simultaneous production of many 2-dimensional paper chromatograms. Science, 112, 621.

Dent, C. E. (1947). Mechanisms of aminoaciduria. Fed. Proc., 6, 390.

- (1948). A study of the behaviour of some sixty amino-acids and other ninhydrin reacting substances on phenol-"collidine" filter paper chromatograms with notes as to the occurrence of some of them in biological fluids. Biochem. J., 43, 169. and Walshe, J. M. (1951). Liver Disease, p. 22. Ciba Foundation Symposium

Dorfman, A. and Lorincz, A. E. (1957). Occurrence of urinary acid mucopolysaccharides in the Hurler syndrome. Proc. nat. Acad. Sci. (Wash.), 43, 443.

Fölling, A. (1934). Über Ausscheidung von Phenylbrenztraubensäure in den Harn als Stoffwechselanomalie in Verbindung mit Imbezillität. Z. physiol. Chem., 227, 169.
Garrod, A. E. (1908). The Croonian Lectures on inborn errors of metabolism, I, II, III, IV. Lancet, 2, 1, 73, 142, 214. (1923). Inborn Errors of Metabolism, 2nd ed. Frande, Hadden and Straighton, London.

Ghadimi, H., Partington, M. W. and Hunter, A. (1961). A familial disturbance of histidine metabolism. New Engl. J. Med., 265, 221.

Harris, H., Penrose, L. S. and Thomas, D. H. (1959). Cystathioninuria. Ann. hum. Genet., 23, 442.

Heremans, J. and Vaerman, J. P. (1958). Différenciation sur papier des protéines et des mucopolysaccharides acides au moyen de des protéines et des mucopolysaccharides acides au moyen de

Hunter, C. (1917). A rare disease in two brothers. Proc. roy. Soc. Med., 10, Sect. Stud. Dis. Child., p. 104.

Hurler, G. (1919). Uber einen Typ multipler Abartungen, vorwiegend am Skelettsystem. Z. Kinderheilk., (Orig.) 24, 220.

Isselbacher, K. J., Anderson, E. P., Kurahashi, K. and Kalckar, H. M. (1956). Congenital galactosemia, a single enzymatic block in galactose metabolism. Science, 123, 635 .

Jervis, G. A. (1953). Phenylpyruvic oligophrenia (phenylketonuria)。 Res. Publ. Ass. nerv. ment. Dis., 33, 259.

- Block, R. J., Bolling, D. and Kanze, E. (1940). Chemical and metabolic studies on phenylalanine; phenylaline content of blood and spinal fluid in phenylpyruvic oligophrenia. J. biol. Chem., 134, 105.

La Du, B. N., Zannoni, V. A., Laster, L. and Seegmiller, J. E. (1958) The nature of the defect in tyrosine metabolism in alcaptonuria. ibid., 230, 251 .

Lowe, C. U., Terrey, M. and MacLachlan, E. A. (1952). Organic aciduria, decreased renal ammonia production, hydrophthalmos and mental retardation; a clinical entity. A.M.A. Amer. J. Dis. Child., 83, 164.

Meyer, K. Hoffman, P. and Linker, A. (1957). Chondroitin sulphate $\mathrm{B}$ and heparitin sulphate. Ann. rheum. Dis., 16, 129.

Milne, M. D., Crawford, M. A., Girao, C. B. and Loughridge, L. W. (1960). The metabolic disorder in Hartnup disease. Quart. J. Med., 29, 407

Penrose, L. S. (1935). Inheritance of phenylpyruvic amentia (phenylketonuria). Lancet, 2, 192.

Reuss, A. von (1908). Zuckerausscheidung im Säuglingsalter. Wien. med. Wschr., 58, 799.

Schwarz, V., Golberg, L., Komrower, G. M. and Holzel, A. (1956) Some disturbances of erythrocyte metabolism in galactosaemia. Biochem. J., 62, 34.

Smith, I. (1960). Chromatographic and Electrophoretic Techniques, 2nd ed., vol. I. Heinemann, London.

Soupart, P. (1954). Contribution à l'étude de l'histidinurie au cours de la grossesse. Le débit urinaire d'histidine au cours du cycle menstruel normal. Acta clin. belg., 9, 297 and 319.

(1960). Aminoacidemia and aminoaciduria during the menstrual cycle in the normal woman. Clin. chim. Acta, 5, 235.

Sprince, H. (1961). Indole metabolism in mental illness. Clin. Chem., 7, 203. 